\title{
A study on seismicity and seismic hazard for Karnataka State
}

\author{
T G Sitharam ${ }^{1}$, Naveen James ${ }^{1, *}$ K S Vipin ${ }^{1}$ and K Ganesha RaJ ${ }^{2}$ \\ ${ }^{1}$ Department of Civil Engineering, Indian Institute of Science, Bangalore 560 012, India. \\ ${ }^{2}$ NNRMS/EOS, ISRO Head Quarters, Antariksh Bhavan, New BEL Road, Bangalore 560 094, India. \\ *Corresponding author.e-mail: naveenjames7@gmail.com
}

\begin{abstract}
This paper presents a detailed study on the seismic pattern of the state of Karnataka and also quantifies the seismic hazard for the entire state. In the present work, historical and instrumental seismicity data for Karnataka (within $300 \mathrm{~km}$ from Karnataka political boundary) were compiled and hazard analysis was done based on this data. Geographically, Karnataka forms a part of peninsular India which is tectonically identified as an intraplate region of Indian plate. Due to the convergent movement of the Indian plate with the Eurasian plate, movements are occurring along major intraplate faults resulting in seismic activity of the region and hence the hazard assessment of this region is very important. Apart from referring to seismotectonic atlas for identifying faults and fractures, major lineaments in the study area were also mapped using satellite data. The earthquake events reported by various national and international agencies were collected until 2009. Declustering of earthquake events was done to remove foreshocks and aftershocks. Seismic hazard analysis was done for the state of Karnataka using both deterministic and probabilistic approaches incorporating logic tree methodology. The peak ground acceleration (PGA) at rock level was evaluated for the entire state considering a grid size of $0.05^{\circ} \times 0.05^{\circ}$. The attenuation relations proposed for stable continental shield region were used in evaluating the seismic hazard with appropriate weightage factors. Response spectra at rock level for important Tier II cities and Bangalore were evaluated. The contour maps showing the spatial variation of PGA values at bedrock are presented in this work.
\end{abstract}

\section{Introduction}

Indian subcontinent is prone to all types of natural hazards of which earthquake is the major one. Tremendous growth in population, rapid urbanization and underrated construction and land use techniques have made most of the cities and towns across the country seismically vulnerable. So to mitigate the seismic hazard, it is necessary to make some scientific earthquake studies for identifying the regions having high intensity of seismic risk. The state of Karnataka is located between $74^{\circ} 6^{\prime}-78^{\circ} 35^{\prime} \mathrm{E}$ longitude and $11^{\circ} 37^{\prime}-18^{\circ} 28^{\prime} \mathrm{N}$ lati- tude. It covers an area of $191,791 \mathrm{~km}^{2}$, or $5.83 \%$ of the total geographical area of India. Karnataka is a prime location for industrial activities as it hosts large number of small and large scale industries and a major center for Information Technology (IT) industry. The capital city of Karnataka, Bangalore, is known as the 'Silicon Valley of India'. Many historical monuments are located in northern parts of Karnataka which makes it significant from the archeological and historical point of view. Due to rapid urbanization, cites in Karnataka are having many infrastructural development activities. Major projects like Metro Rail project have already been

Keywords. Karnataka; earthquakes; PGA; PSHA; DSHA; hazard; lineaments; faults logic tree. 
initiated in Bangalore. Thus, scientific estimate of various hazards is a decisive factor for urban planning with disaster management measures. Major earthquakes reported in the region were at Bellary $\left(M_{w} 5.7\right.$ in 1843), Koyna $\left(M_{w} 6.1\right.$ in 1967), Hassan $\left(M_{w} 5.6\right.$ in 1970), Latur $\left(M_{w} 6.1\right.$ in 1993) and Coimbatore $\left(M_{w} 6.0\right.$ in 1900). As per the seismic zoning given by BIS-1893 (2002), shown in figure 1, the state of Karnataka lies in Zones II and III, and this zoning is based on geology and the past seismic activity and not based on peak horizontal acceleration (PHA) values. For proper estimation of earthquake hazard, first step is the delineation of all the seismic sources and events in the study area, then the estimation seismicity parameters for the region and finally the assessment of seismic hazard using seismic data and the frequency dependent regional attenuation relation.

Seismic hazard for a place can be estimated using two methodologies; they are Probabilistic Seismic Hazard Analysis (PSHA) and Deterministic Seismic Hazard Analysis (DSHA). DSHA approach is event oriented, considers only a few (or sometimes only one) earthquakes that are expected to produce the most severe ground motion at a site. Designs based on ground motion estimated from DSHA will be on the conservative side and hence suitable for critical structures like dams, nuclear power plants, etc. On the other hand, PSHA can incorporate the effect of different events, bigger as well as smaller, on the hazard value at the site. Methodically DSHA is straight forward and

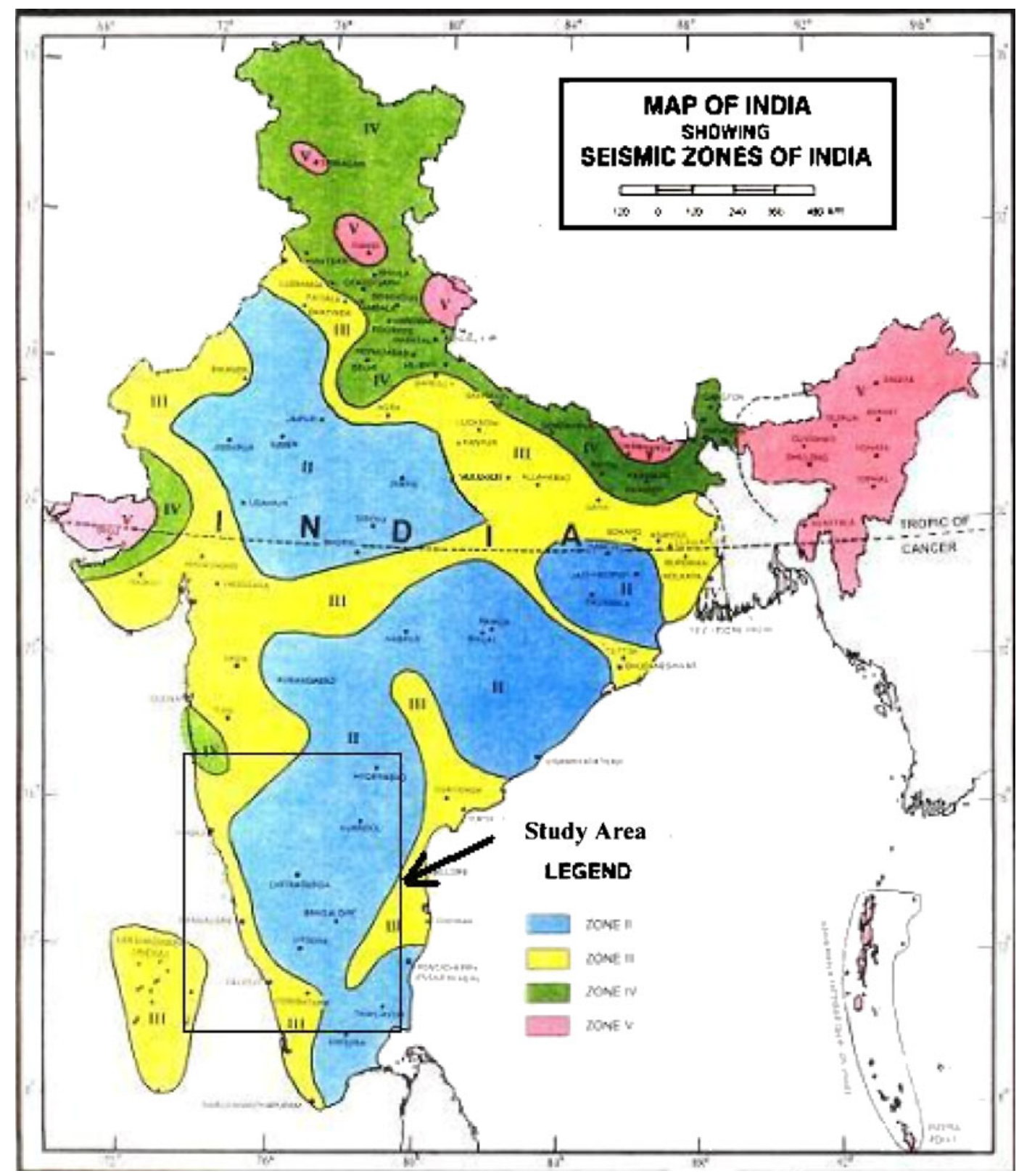

Figure 1. Seismic zonation map of India highlighting the study area (BIS-1893 2002, page 5). 
simple compared to PSHA where lot of uncertainties need to be addressed. PSHA can successfully yield the seismic hazard values for various return periods and helps the designer to choose a particular hazard value corresponding to the structure's life span. Major limitations of PSHA are:

- it is difficult to explain the physical meaning of the ground motion obtained from PSHA,

- the statistical characteristics of ground motion are not clear or lost in PSHA, and

- PSHA provides ground motion corresponding to any mean annual rate of exceedance and so it does not provide a unique choice for users and decision makers (Wang 2005).

Hence both the methods were performed for evaluating seismic hazard for the state of Karnataka.

The seismic regionalization studies to demarcate areas of potential earthquake damage in the Indian subcontinent were done by Tandon (1956) and Krishna (1959). Guha (1962) and Gubin (1968) then introduced the intensity-based mapping of seismic hazard of the Indian subcontinent. Earliest works for assessing seismic hazard of Indian subcontinent using probabilistic method were done by Basu and Nigam (1977), Kaila and Rao (1979), Khatri et al (1984) and Bhatia et al (1999) as a part of the global seismic hazard assessment programme (GSHAP). Deterministic seismic hazard assessment for the Indian subcontinent was done by Parvez et al (2003). Studies by Jaiswal and Sinha (2007) and Vipin et al (2009) were specifically focused on seismic hazard assessment of peninsular India. Walling and Mohanty (2009) have presented a comprehensive review of all major hazard assessment works carried out for the Indian subcontinent and its various regions.

In the present study, seismicity analysis and seismic hazard assessment are done for the state of Karnataka. Earthquake catalogue for the study area is prepared covering the period of 1594 to 2009. Earthquake sources are identified using both SEISAT (2000) and also using satellite data. Hazard analysis is carried out using deterministic and probabilistic method along with logic tree approach. For deterministic study, two types of source models - point source model and linear source model, and for probabilistic approach, linear source model and areal source model are considered. Attenuation relations proposed by Toro et al (1997), Atkinson and Boore (2006) and Raghu Kanth and Iyengar (2007) are used in the analysis.

\section{Seismicity of Karnataka State}

The state of Karnataka constitutes a part of one of the most prominent and largest Precambrian shield areas of the world, and is tectonically termed as intraplate region or shield region. The convergent movement of Indian plate towards Eurasian plate at the rate of $5 \mathrm{~cm} /$ year (Kumar et al 2007) induces moderate to high deformations in the interior of the Indian plate and therefore, the peninsular India can no longer be considered as a stable landmass with low seismicity. Major earthquakes including Coimbatore $\left(6.0 M_{w}\right.$ in 1900) was felt over an area of about $250,000 \mathrm{~km}^{2}$ in south India, Koyna of $M_{w} 6.1$ in 1967 , also felt over a radius of $700 \mathrm{~km}$, killing 177 people and 2232 people were injured (Chandra 1977), Latur of $M_{w} 6.1$ in 1993 where over 10,000 lives were lost and several villages were destroyed (Jain et al 1994). These earthquakes have changed the long-held image of low seismic activity of peninsular India and encouraged the earth scientists to investigate the seismicity and tectonics of the region. Studies by Chandra (1977) points that some of these earthquakes were felt over a much larger area than one would expect earthquakes of equivalent magnitude to be felt in most other parts of the world. Iyengar et al (1999) listed out major earthquakes that had occurred in peninsular India during Medieval time. From the regional earthquake data of two decades (19781997), obtained from Gauribidanur seismic array, Gangrade and Arora (2000) also showed that seismicity of Indian peninsular shield is higher than what was expected. Rao (2000) showed that the increase in intraplate deformation in the lithosphere of the Indian peninsular shield and the strain rates for the Indian shield as a whole is found to be the second highest in stable continental regions (SCR) of the world (the highest being the North America). More over, remote sensing studies by Ramasamy (2006) revealed that the southern part of the Indian peninsula is tectonically active due to the northerly to northnortheasterly directed compressive force related to post-collision tectonics. All these studies point to the fact that peninsular India, which is otherwise called stable continental region, should no longer be considered as a region of low seismicity. As the Karnataka State forms a part of the peninsular India, its seismicity should be properly assessed through accurate seismic hazard analysis and effective mitigation steps need to be taken.

\section{Preparation of the seismotectonic atlas for Karnataka}

A typical seismotectonic atlas of a region shows all major tectonic features like faults and spatial distribution of earthquake events from historic (up to 1900), pre-instrumentation (from 1901-1963) and instrumentation (1964 onwards) period of that 
area. It also delineates different types of faults like strikeslip fault, gravity fault, neotectonic fault, etc. Preparation of seismotectonic atlas for a region is the first and foremost step to evaluate seismic hazard for that region.

\subsection{Data collection}

While evaluating the seismic hazard of a region the first step is the compilation of an earthquake catalogue for the study area. In the present study, the earthquake catalogue was prepared by extracting data from different sources such as, India Meteorological Department (IMD), National Geophysical Research Institute (NGRI) Hyderabad, Gauribidanur Array of BARC, Indira Gandhi Center for Atomic Research (IGCAR) at Kalpakkam, etc., and International agencies like United States Geological Survey (USGS), International Seismological Centre (ISC) UK, Incorporated Research Institutions for Seismology (IRIS), Northern California Earthquake Data Center (NCEDC), etc. Earthquake events within $300 \mathrm{~km}$ radius from the political boundary of Karnataka State were collected along with epicentral coordinates, focal depth, magnitude, time, date and year of occur- rence. All events are converted into moment magnitude scale $\left(M_{w}\right)$ using suitable relations proposed by Scordilis (2006) and Heaton et al (1986). The intensity values were converted using the equation suggested by Reiter (1990).

\subsection{Declustering the data}

Events collected from these sources comprise foreshocks and aftershocks apart from the mainshock which are not relevant for hazard analysis. Lots of events in the catalogue were repetitive as these are reported by more than one agency. These events are to be declustered so that the resulting database is free from repetitive events, foreshocks, aftershocks. Since the seismic activity in the study area is moderate when compared to any active plate boundary region, a time window of 30 days and $30 \mathrm{~km}$ distance between the reported events were used for declustring the events. The same method was followed by Vipin et al (2009) and Sitharam and Vipin (2011) and a similar methodology for declustring was adopted by Jaiswal and Sinha (2007). From the set of events pertaining to a frame of 30 days and $30 \mathrm{~km}$, the event with largest magnitude was selected as mainshock

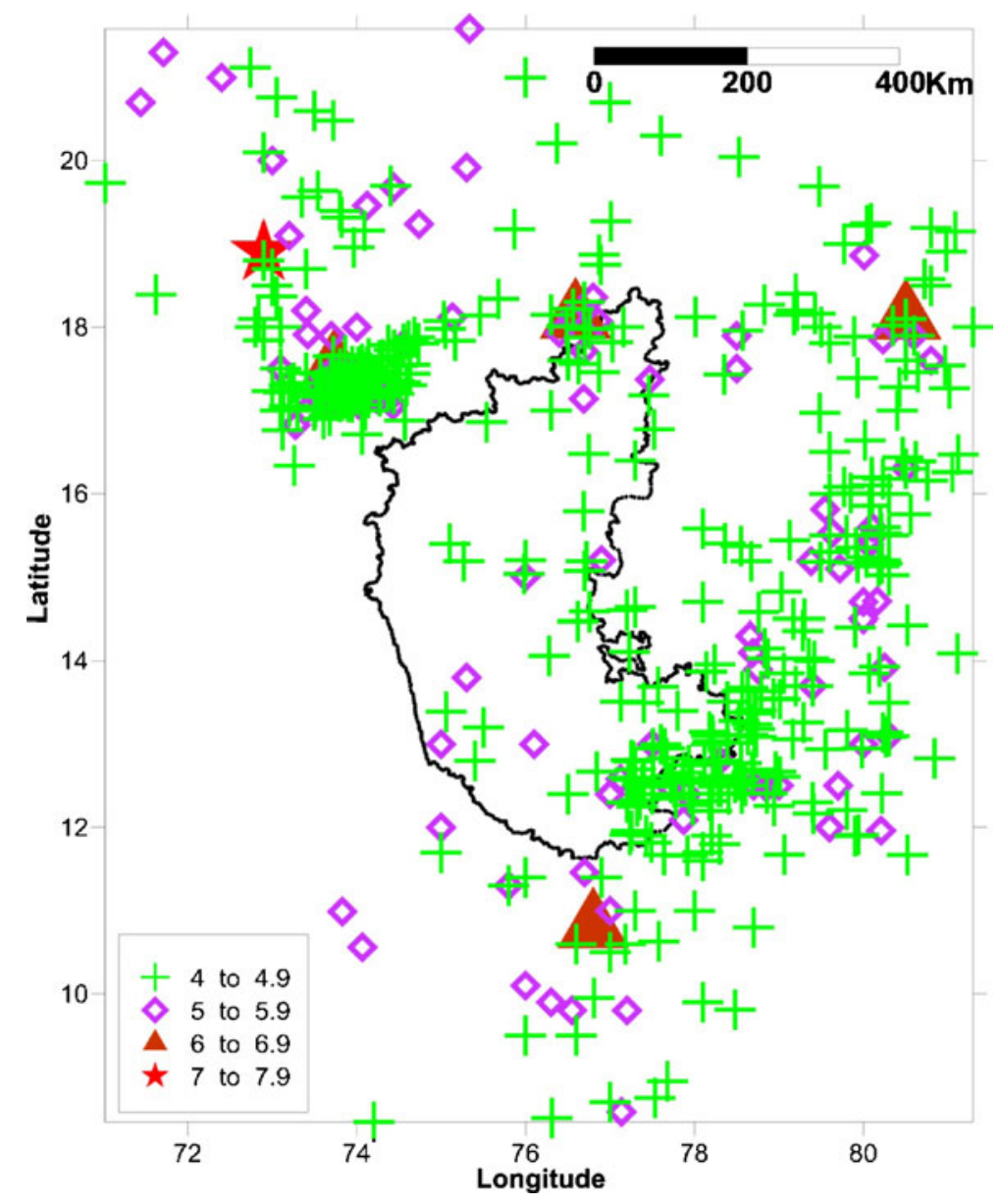

Figure 2. Earthquake events in the study area (having magnitude 4 and above) along with a map of the study area. 
and rest were rejected from the catalogue. After declustring, there are about 1678 seismic events in the study area and out of which 555 events are of magnitude 4 and above (figure 2). All these events were georeferenced and superimposed in the Karnataka map and this map was used in this study.

\subsection{Mapping of fault and lineaments}

The tectonic features of the study area like faults and lineaments were mapped from the seismotectonic atlas (SEISAT 2000) published by Geological Survey of India (GSI) and also using satellite data.

\subsubsection{Fault and lineament mapping by SEISAT 2000}

Seismotectonic atlas (SEISAT 2000) contains 43 maps covering entire India and adjoining areas of bordering countries, with all available data related to earthquakes. It is a compilation of multi- thematic database comprising of 43 maps (presented in 42 sheets) of $3^{\circ} \times 4^{\circ}$ size covering India and adjacent regions of neighbouring countries on 1:1 million scale. Sheets in SEISAT representing the features of study area were scanned separately with 300 dpi resolution to get high quality digital images and these were georeferenced using MapInfo Professional Version 6.0. After this, the tectonic features were carefully picked and superimposed on to a map of study area.

\subsubsection{Fault and lineament mapping using satellite data}

In addition to referring seismotectonic atlas, the major lineaments (with length more than $100 \mathrm{~km}$ ) of Karnataka State, were mapped using satellite data (Indian Remote Sensing Satellite (IRS)1D, Wide Field Sensor (WiFS) and Landsat Multi Spectral Scanner (MSS)/Thematic Mapper (TM) data) on 1:1 million scale. The length and direction of each lineament were measured and

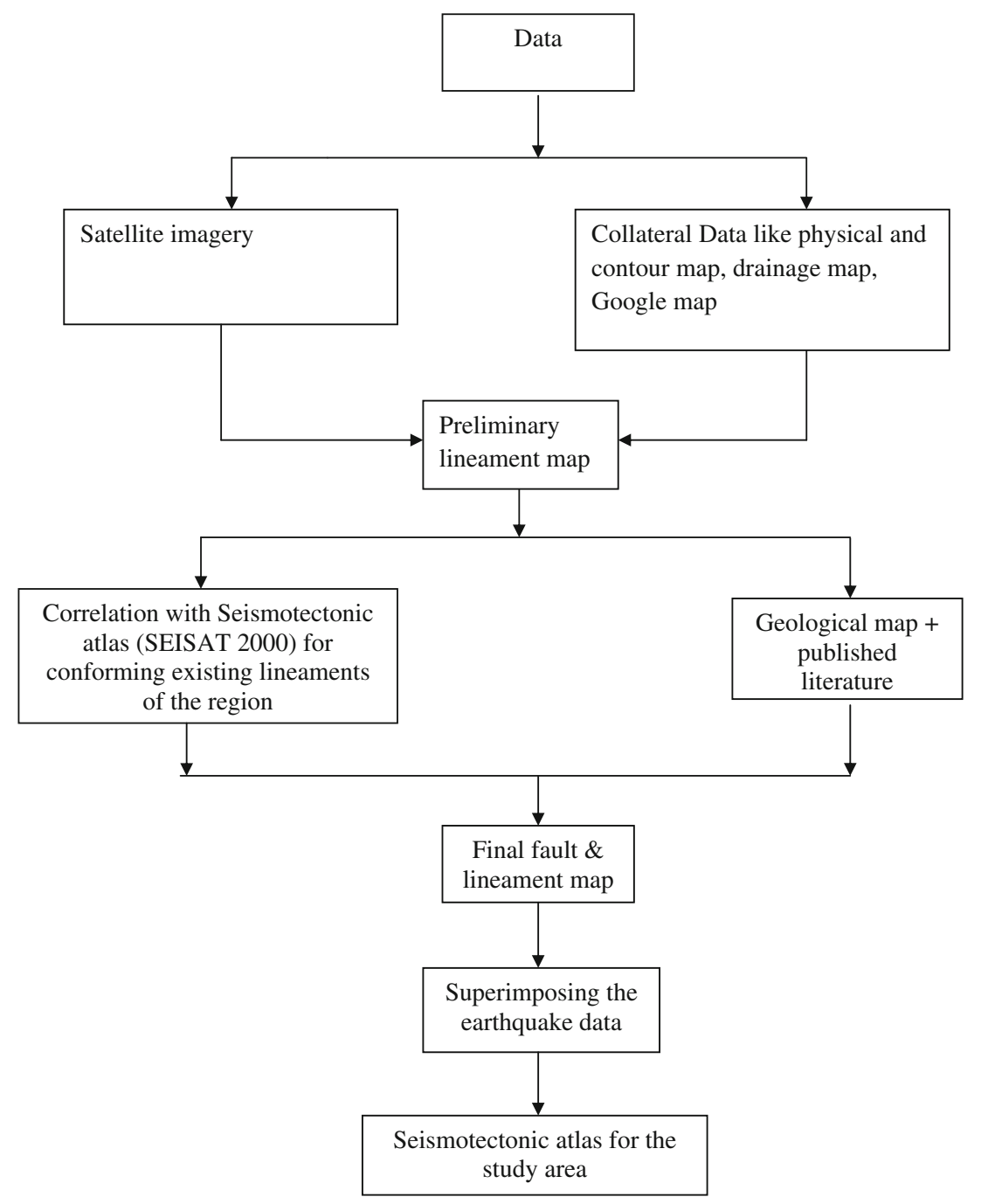

Figure 3. Methodology for lineament/fault identification and development of seismotectonic map. 
the lineaments were grouped based on length and direction. The nature of each lineament was assessed using the satellite data in conjunction with the collateral data. Remote sensing data due to its synoptic nature is found to be very useful in mapping lineaments. Images taken in the near infrared (NIR) region $(0.7-1.1 \mu \mathrm{m})$ depict clearly more lineaments than other bands. Radar data also provides information on lineaments due to its oblique look angles. Thermal infra-red (TIR) data is found to be useful in delineating wet lineaments with moisture/water. Lineaments present in the forest areas and soil covered areas are also clearly visible on images thus enabling us to delineate better structural features.

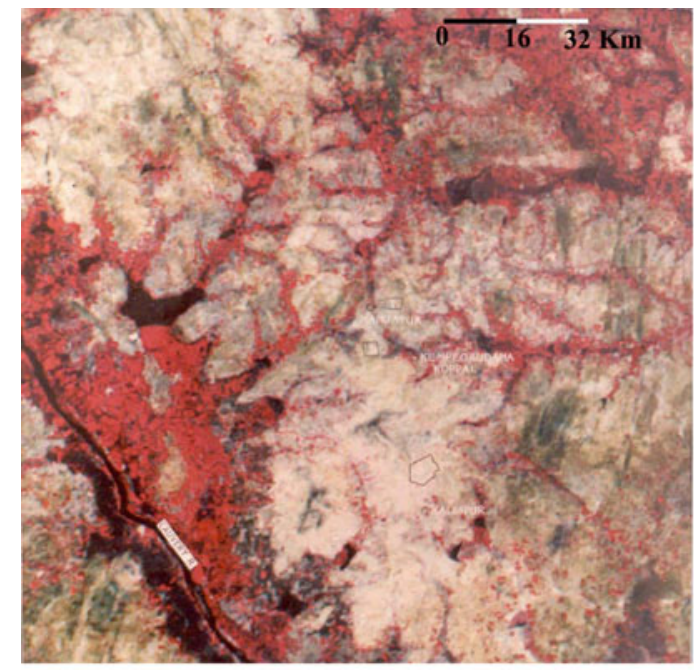

(a) Cauvery lineament

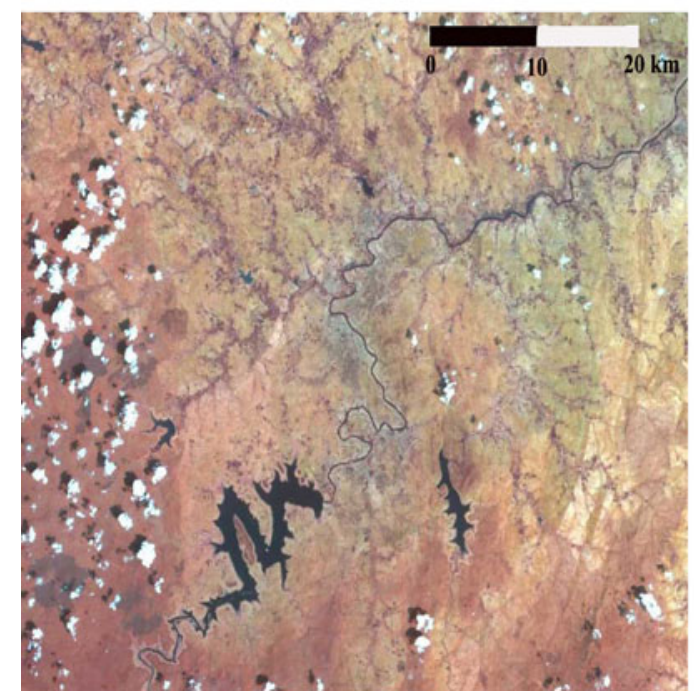

(c) Kabini lineament
A lineament is a linear feature of a surface whose parts align in a straight or slightly curving relationship and that differs distinctly from the patterns of adjacent features. Normally, it is difficult to decide whether the mapped lineament is a fault or not, but if there is a clear displacement/offset then the lineament can be identified as a fault. Integration of the lineament map with the available structural and geological information of the terrain plus fieldwork helps to decide the nature of the lineament.

Lineaments, which are seen as linear features on satellite data were mapped. A typical schematic showing the methodology of lineament mapping is shown in figure 3 . Lineaments with length more

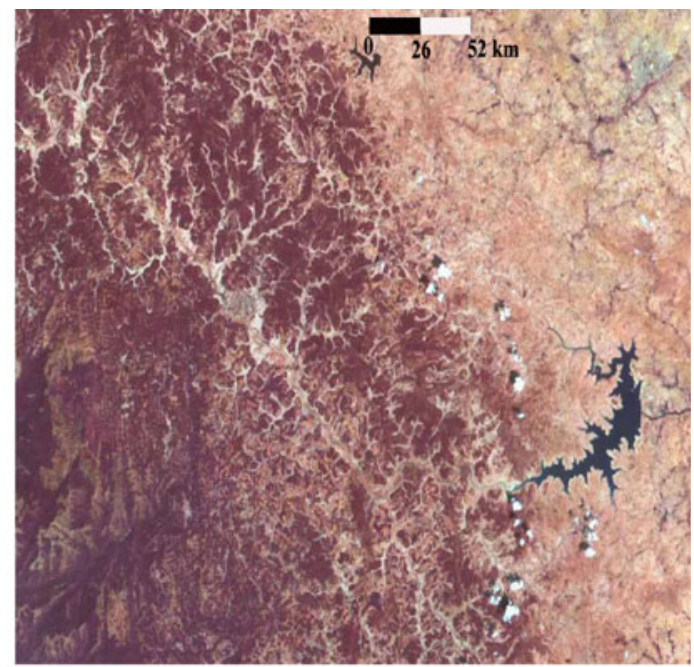

(b) Hemavathy-Thirthahalli lineament

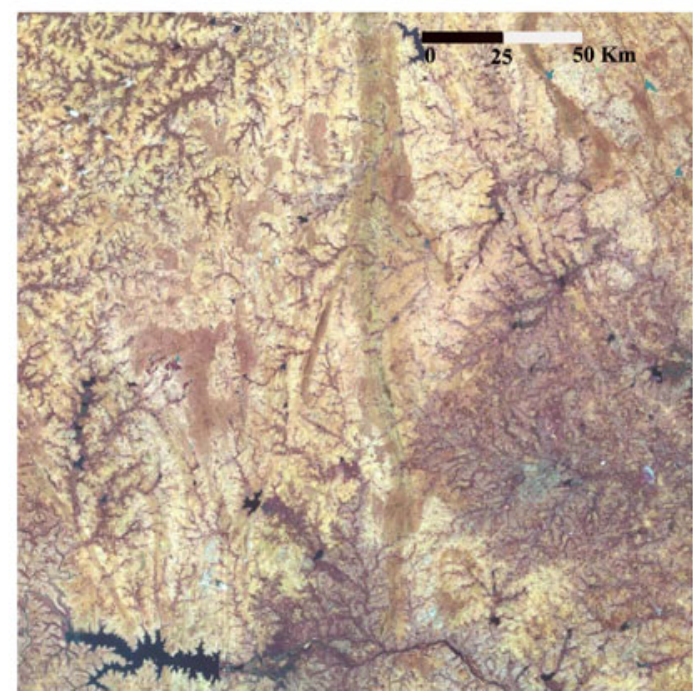

(d) Arkavathi - Madhugiri lineament

Figure 4. IRS LISS-II images showing various lineaments in Karnataka (extracted from RS image procured from National Remote Sensing Agency in the year 2006). (a) Cauvery lineament, (b) Hemavathy-Thirthahalli lineament, (c) Kabini lineament, and (d) Arkavathi-Madhugiri lineament. 
than $100 \mathrm{~km}$, i.e., major lineaments were mapped first from individual scenes of Landsat data on 1:1 million scale scenes; these were transferred to base map of Karnataka on 1:1 million scale to make a single map. This map was superimposed on physical/road network map of Karnataka to eliminate any cultural lineament like road, railway lines which also appear as lineaments in the satellite image. IRS-1D WiFS FCC (figure 4) on 1:1 million scale was used further to map the lineaments. Lineaments were numbered and their length and direction were measured.

Studies were done to see the correlation between major lineaments and earthquake occurrence, to identify seismically active lineaments. Earthquakes with magnitude 4 and above that occurred in Karnataka and regions inside $300 \mathrm{~km}$ from the Karnataka State boundary were considered and overlaid on major lineament map of Karnataka and adjoining regions to assess the correlation between earthquakes and major lineaments. Currently, along many lineaments rivers/streams are flowing. Parts of the river courses of Hemavathi, Tunga, Yagachi, Vedavathi, Krishna, Nethravathi, Malaprabha, etc., follow major lineaments. The major lineaments in the study area, which have some correlation with the occurrence of earthquakes, were identified and shown in figure 5.

The declustered earthquake data was superimposed on to the georeferenced lineament/fault map. All the lineaments/faults which were associated with earthquakes of magnitude 4 and above were identified as active seismic sources. About 163 faults in the study area ranging from 12 to $531 \mathrm{~km}$ in length were identified and mapped. A map of the seismic study area (constituting Karnataka and region within $300 \mathrm{~km}$ from the boundary of Karnataka) along with the earthquake events and

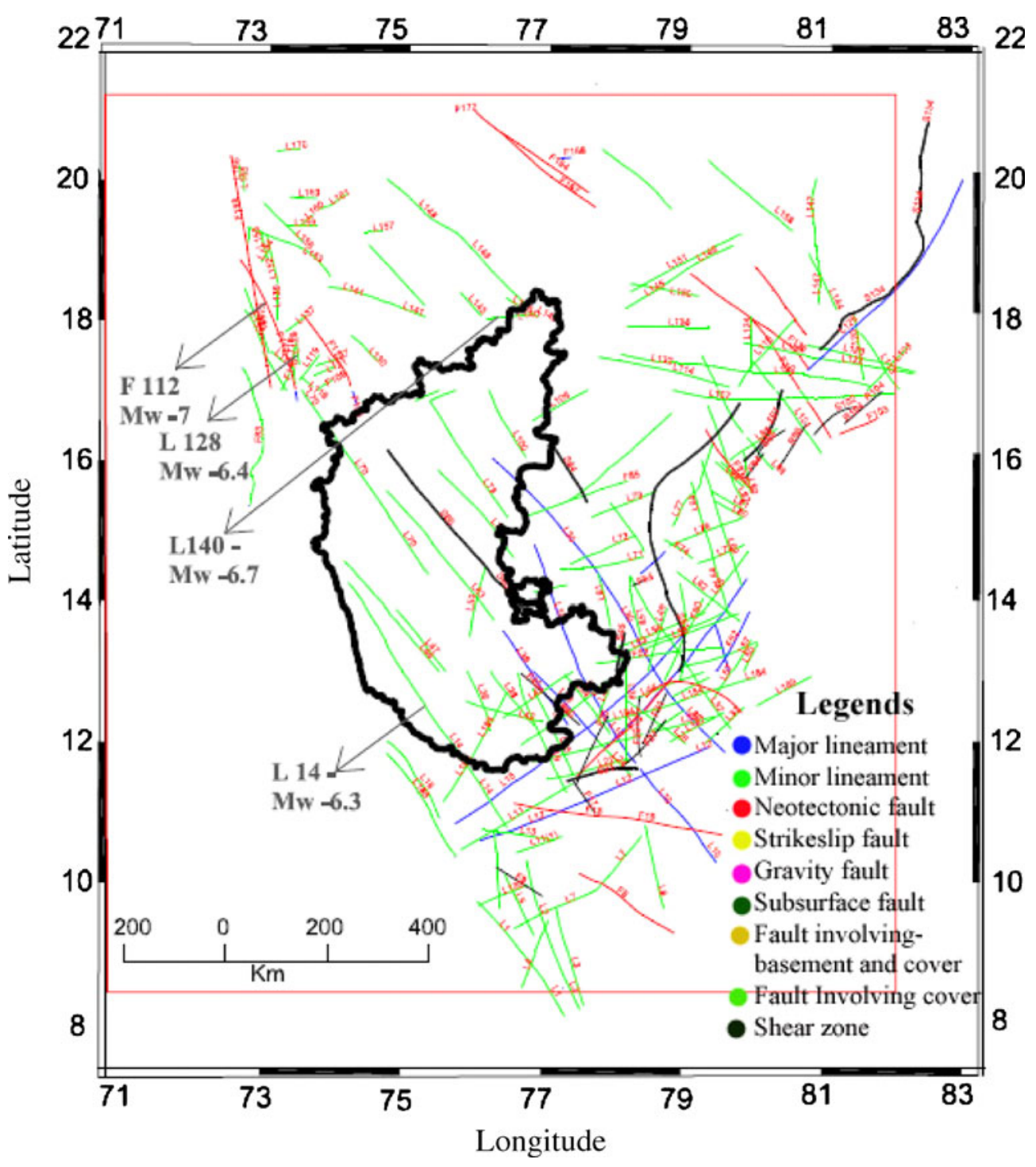

Figure 5. Map showing active lineaments/faults having earthquake events $\left(M_{w}\right)$ greater than 4 in the study area. (Note: Faults and lineaments in the Arabian Sea are not available and hence not considered in the study.) 


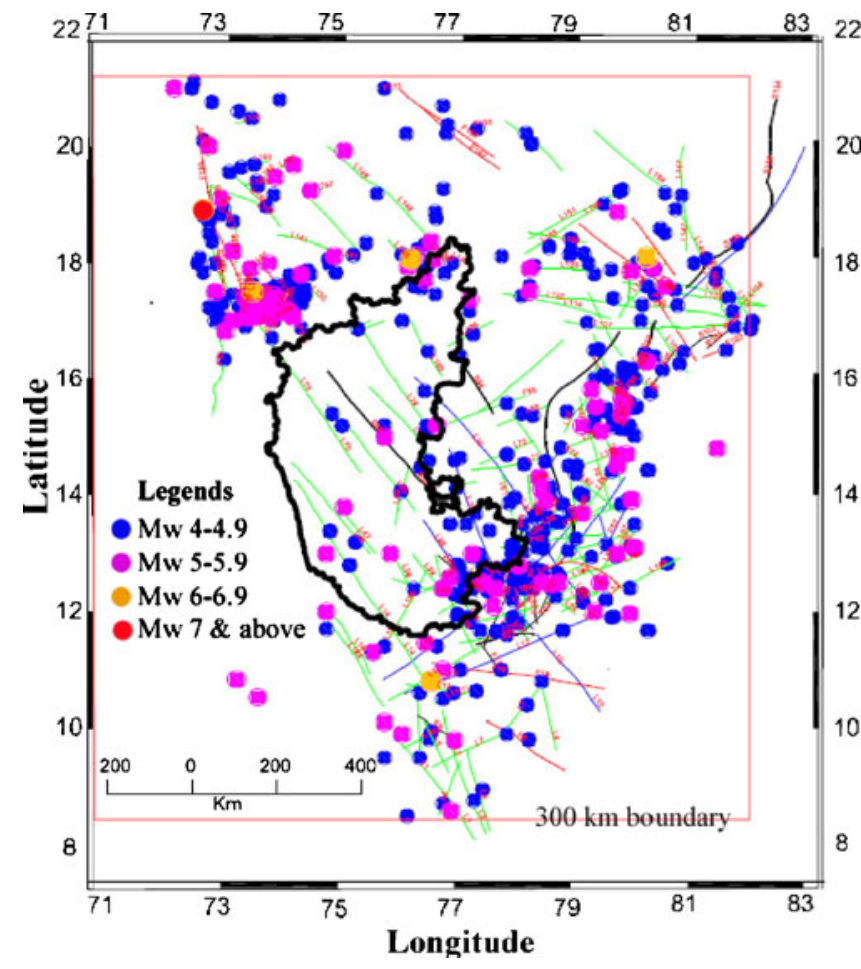

Figure 6. Sesimotectonic atlas of Karnataka showing faults/ lineaments along with events having magnitude 4 and above.

identified linear seismic sources are shown in figure 6. Fault details like length and earthquake capacity (having $M_{w}$ more than 5) is presented in tables 1 and 2.

\section{Seismicity analysis for Karnataka}

The seismic activity of a region is characterized by the Gutenberg-Richter earthquake recurrence law (Gutenberg and Richter 1944). According to this law,

$$
\log _{10} N=a-b M
$$

where $N$ is the total number of earthquakes with magnitude $M$ and above which will occur in a year (mean annual rate of exceedance) and ' $a$ ' and ' $b$ ' are the seismicity parameters of the region. These values signify the background seismicity and the magnitude size distribution for the region respectively. Since the study area is small with only 1678 events, single set of parameters were used to address the seismicity of the region. Statistical method proposed by Stepp (1972) was used to analyze the completeness of the catalogue. This method will give the time interval in which a magnitude range is homogeneous. The seismicity parameters were evaluated based on the complete part of the catalogue. The earthquake recurrence
Table 1. Major lineaments in the study area having earthquake magnitude more than 5.

\begin{tabular}{|c|c|c|c|c|c|}
\hline No. & $M_{\max }$ & $\begin{array}{c}\text { Length } \\
\text { (approx. km) }\end{array}$ & No. & $M_{\max }$ & $\begin{array}{c}\text { Length } \\
\text { (approx. km) }\end{array}$ \\
\hline 1 & 7 & 220 & 34 & 5.2 & 83 \\
\hline 2 & 6.7 & 67 & 35 & 5.1 & 231 \\
\hline 3 & 6.4 & 35 & 36 & 5.1 & 84 \\
\hline 4 & 6.3 & 457 & 37 & 5.1 & 138 \\
\hline 8 & 5.9 & 50 & 38 & 5.1 & 229 \\
\hline 9 & 5.8 & 43 & 39 & 5 & 143 \\
\hline 10 & 5.7 & 470 & 40 & 5 & 347 \\
\hline 11 & 5.7 & 283 & 41 & 5 & 166 \\
\hline 12 & 5.7 & 35 & 42 & 5 & 118 \\
\hline 13 & 5.7 & 57 & 43 & 5 & 49 \\
\hline 14 & 5.7 & 40 & 44 & 5 & 107 \\
\hline 15 & 5.7 & 31 & 45 & 5 & 107 \\
\hline 16 & 5.7 & 351 & 46 & 5 & 219 \\
\hline 17 & 5.6 & 100 & 47 & 5 & 125 \\
\hline 18 & 5.6 & 131 & 48 & 5 & 332 \\
\hline 19 & 5.6 & 372 & 49 & 5 & 21 \\
\hline 20 & 5.4 & 123 & 50 & 5 & 207 \\
\hline 21 & 5.4 & 120 & 51 & 5 & 349 \\
\hline 22 & 5.4 & 148 & 52 & 5 & 76 \\
\hline 23 & 5.3 & 200 & 53 & 5 & 57 \\
\hline 24 & 5.3 & 26 & 54 & 5 & 62 \\
\hline 25 & 5.3 & 109 & 55 & 5 & 35 \\
\hline 26 & 5.2 & 176 & 56 & 5 & 36 \\
\hline 27 & 5.2 & 146 & 57 & 5 & 379 \\
\hline 28 & 5.2 & 286 & 58 & 5 & 47 \\
\hline 29 & 5.2 & 109 & 59 & 5 & 27 \\
\hline 30 & 5.2 & 84 & 60 & 5 & 160 \\
\hline 31 & 5.2 & 57 & 61 & 5 & 241 \\
\hline 32 & 5.2 & 124 & - & - & - \\
\hline 33 & 5.2 & 283 & - & - & - \\
\hline
\end{tabular}

rate obtained for the study area is shown schematically in figure 7 . The values obtained for parameters ' $a$ ' and ' $b$ ' were 4.754 and 0.923 , respectively. The obtained values of ' $a$ ' and ' $b$ ' are comparable with that of earlier studies by Anbazhagan et al (2009) for Bangalore, Vipin et al (2009) for south India and Menon et al (2010) for Tamil Nadu (table 3).

\section{Seismic hazard assessment for Karnataka}

As mentioned in the introductory part of this paper, two methodologies (deterministic hazard analysis and probabilistic seismic hazard analysis) are used to estimate hazard for the Karnataka State.

\subsection{Deterministic seismic hazard analysis (DSHA)}

In deterministic seismic hazard analysis (DSHA), only the maximum magnitude is assigned to a particular source and shortest distance (hypocentral 
Table 2. Major lineaments in the study area having earthquake magnitude more than 6 .

\begin{tabular}{|c|c|c|c|c|c|c|c|c|}
\hline \multirow[b]{2}{*}{ Sl. no. } & \multirow[b]{2}{*}{ Fault no. } & \multicolumn{2}{|c|}{ Starting co-ordinates } & \multicolumn{2}{|c|}{ End point co-ordinates } & \multirow{2}{*}{$\begin{array}{c}\text { No. of } \\
\text { earthquakes }\end{array}$} & \multirow[b]{2}{*}{$M_{\max }$} & \multirow{2}{*}{$\begin{array}{c}\text { Fault } \\
\text { length }(\mathrm{km})\end{array}$} \\
\hline & & Latitude & Longitude & Latitude & Longitude & & & \\
\hline 1 & F112 & 17.0191 & 73.7048 & 18.8571 & 72.9231 & 11 & 7 & 221.97 \\
\hline 2 & L140 & 18.0201 & 76.4305 & 18.0857 & 77.0633 & 8 & 6.7 & 70.70 \\
\hline 3 & L128 & 17.3677 & 73.7585 & 17.6791 & 73.7134 & 5 & 6.4 & 34.97 \\
\hline 4 & L14 & 10.7814 & 76.7127 & 14.2538 & 74.4556 & 3 & 6.3 & 460.26 \\
\hline
\end{tabular}

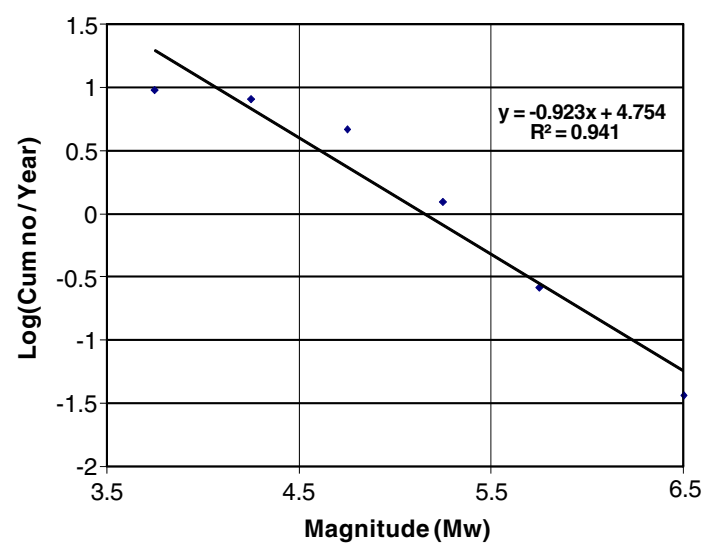

Figure 7. Magnitude recurrence relation for the entire study area obtained based on Stepp's approach.

Table 3. Values of ' $b$ ' compared with published literature.

\begin{tabular}{|c|c|c|}
\hline $\begin{array}{l}\text { Researchers } \\
\text { (and study area) }\end{array}$ & $b$ value & $\begin{array}{c}\text { Data analyzed } \\
\text { for a period } \\
\text { (years) }\end{array}$ \\
\hline $\begin{array}{l}\text { Ram and Rathor (1970) } \\
\text { (for south India) }\end{array}$ & 0.81 & 70 \\
\hline $\begin{array}{l}\text { Kaila et al (1972) } \\
\text { (for south India) }\end{array}$ & 0.70 & 14 \\
\hline $\begin{array}{l}\text { Ramalingeswara Rao and } \\
\text { Sitapathi Rao (1984) } \\
\text { (for south India) }\end{array}$ & 0.85 & 170 \\
\hline $\begin{array}{l}\text { Jaiswal and Sinha (2007) } \\
\text { (for south India) }\end{array}$ & 0.92 & 160 \\
\hline $\begin{array}{l}\text { Anbazhagan et al (2009) } \\
\text { (for Bangalore) }\end{array}$ & 0.86 & 200 \\
\hline $\begin{array}{l}\text { Vipin et al (2009) } \\
\text { (for south India) }\end{array}$ & 0.891 & 400 \\
\hline $\begin{array}{l}\text { Menon et al (2010) } \\
\text { (for south India) }\end{array}$ & 1.13 & 501 \\
\hline $\begin{array}{l}\text { Current study (for Karnataka } \\
\text { and adjoining area) }\end{array}$ & 0.923 & 400 \\
\hline
\end{tabular}

distance) from source to site is considered for the analysis. Knowing the maximum magnitude that can occur at a source and the shortest distance between that source and the site, the peak horizontal acceleration (PHA) at that site is estimated using frequency dependent attenuation relation.
For the analysis the whole state of Karnataka was divided into a grid size of $0.05^{\circ} \times 0.05^{\circ}(5 \times 5 \mathrm{~km})$ and a MATLAB program was developed to evaluate PGA at the center of each grid. Since the deterministic methodology considers the worst scenario, it projects a high value of hazard for that region which normally does not occur in the life span of common structures. However, DSHA is not free from epistemic uncertainty, which reflects the incomplete knowledge of the earthquake occurrence process, like the source characterization, prediction of PHA and $S_{a}$. In the present study, the epistemic uncertainties in source model and attenuation relation have been addressed using a logic tree approach (Bommer et al 2005). Logic tree consists of a series of nodes and several models can be assigned to each node as different branches with different weightages. Allotment of these weightages to different branches is subjective and depends upon the degree of uncertainties in the model, and its accuracy. The sum of all weightages of different branches at a particular node must be unity. Two types of seismic sources - linear and smoothed point sources (Costa et al 1993; Panza et al 1999) were considered in the analysis. Since both the types of sources were of equal importance, equal weightages were assigned to each of them. For both the sources, the focal depth was taken as $15 \mathrm{~km}$. This depth was arrived by considering the focal depth of past events in the region. Similar focal depth was adopted by Sitharam et al (2006) and Anbazhagan et al (2009) for seismic hazard studies of Bangalore.

To model the attenuation properties of the region, three attenuation relations were used, viz., Toro et al (1997), Atkinson and Boore (2006) and Raghu Kanth and Iyengar (2007). The attenuation relation proposed by Raghu Kanth and Iyengar (2007) was given higher weightage of 0.5 since it was developed for peninsular Indian region. The attenuation relation by Atkinson and Boore (2006), which was developed for Eastern North American shield region, was given the second highest weightage of 0.3 and Toro et al (1997) was given the least weightage of 0.2 . Typical logic tree structure employed in DSHA is given in figure 8(a). Response spectra at rock level for important Tier II 

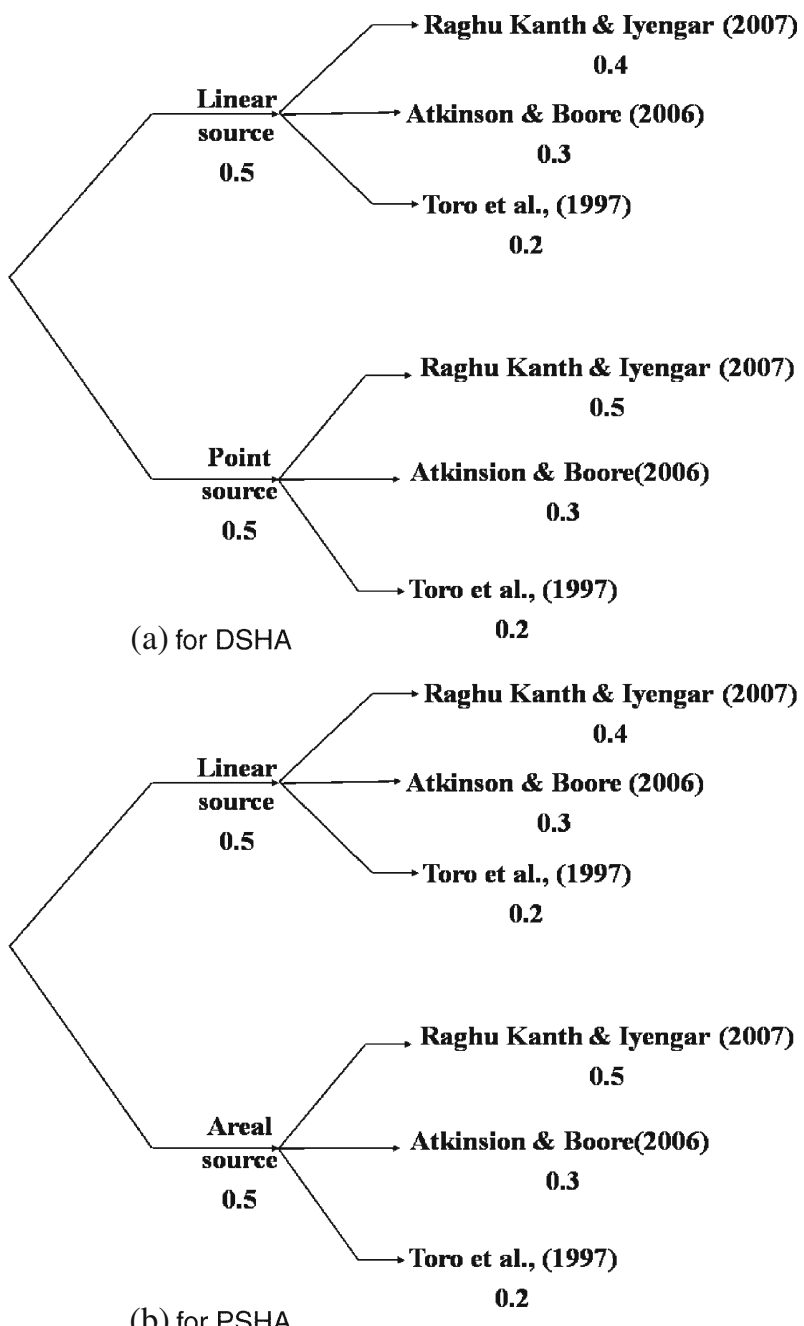

Figure 8. Logic tree structure adopted in the present study for treating epistemic uncertainties in the hazard analysis.

cities and Bangalore in Karnataka were evaluated for eight different periods of oscillations, and the results are presented in this paper.

\subsection{Probabilistic seismic hazard analysis (PSHA)}

Probabilistic seismic hazard analysis (PSHA) was initially developed by Cornell (1968). In reality, the seismic hazard at a site is influenced by all the earthquakes with different magnitudes and different distances and so PSHA considers the contribution of all earthquakes in that region. PSHA also considers the uncertainties associated with time of occurrences of earthquakes and its location. It also provides a framework where these uncertainties can be combined rationally to provide more complete picture of seismic hazard (Kramer 1996). In the probabilistic approach, effects of all the earthquakes expected to occur at different locations during a specified life period are considered along with associated uncertainties and randomness of earthquake occurrences and attenuation of seismic waves with distance. Also PSHA produces uniform hazard response spectrum (UHRS), which is a convenient tool to compare the hazard representations of different sites.

But PSHA only accounts for the uncertainties in the parameters of a particular seismic model and the uncertainties involved in different models may make the selection of a seismic hazard model difficult for this region. Thus the use of logic tree in PSHA (figure 8b) provides a convenient framework for explicit treatment of model uncertainty. Two types of seismic sources with equal weightage - linear sources and smoothed gridded areal sources (Frankel 1995) were considered in the analysis. Smoothed gridded areal sources can also account the earthquake events which are not falling along any of the identified faults, thus giving a better picture of seismic hazard. The hypocentral distance was calculated by considering a focal depth of $15 \mathrm{~km}$, as in the case of DSHA method. A MATLAB program was developed to evaluate the peak ground acceleration (PGA) at rock level for the entire state considering a grid size of $0.05^{\circ} \times 0.05^{\circ}$ $(5 \times 5 \mathrm{~km})$. The attenuation relations proposed by Toro et al (1997), Atkinson and Boore (2006) and Raghu Kanth and Iyengar (2007) were used in the analysis with same weightages as in DSHA. Response spectra corresponding to 475 years and

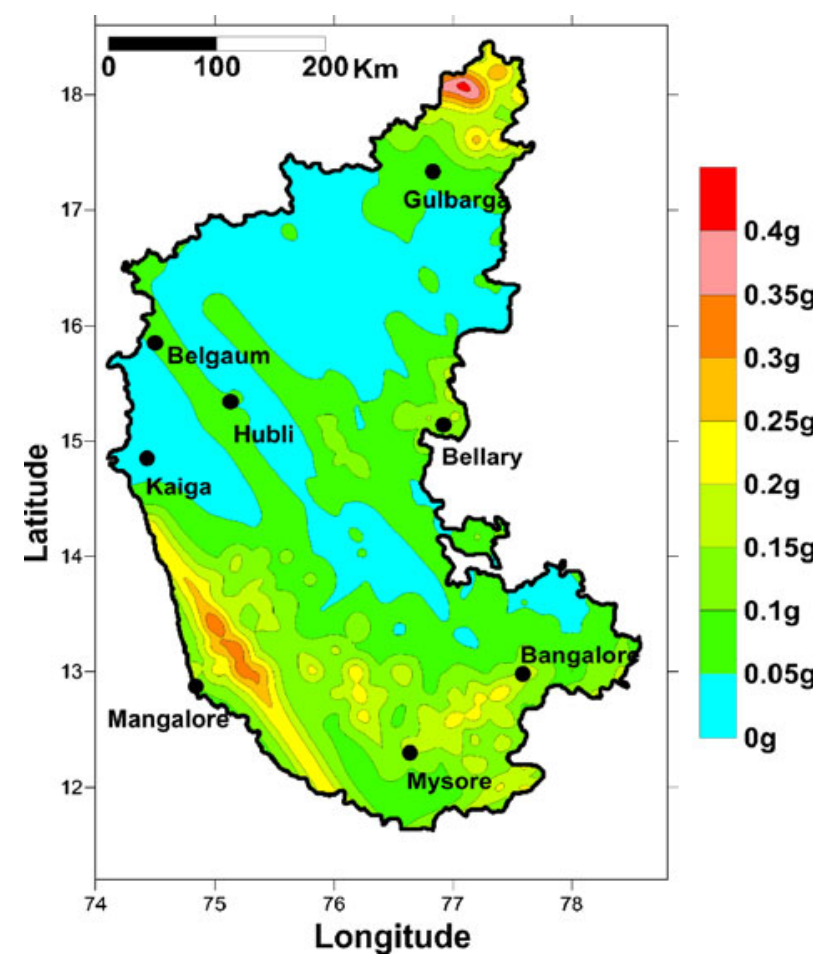

Figure 9. Spatial variation of mean PHA (g) values at bedrock throughout the state of Karnataka (from DSHA). 


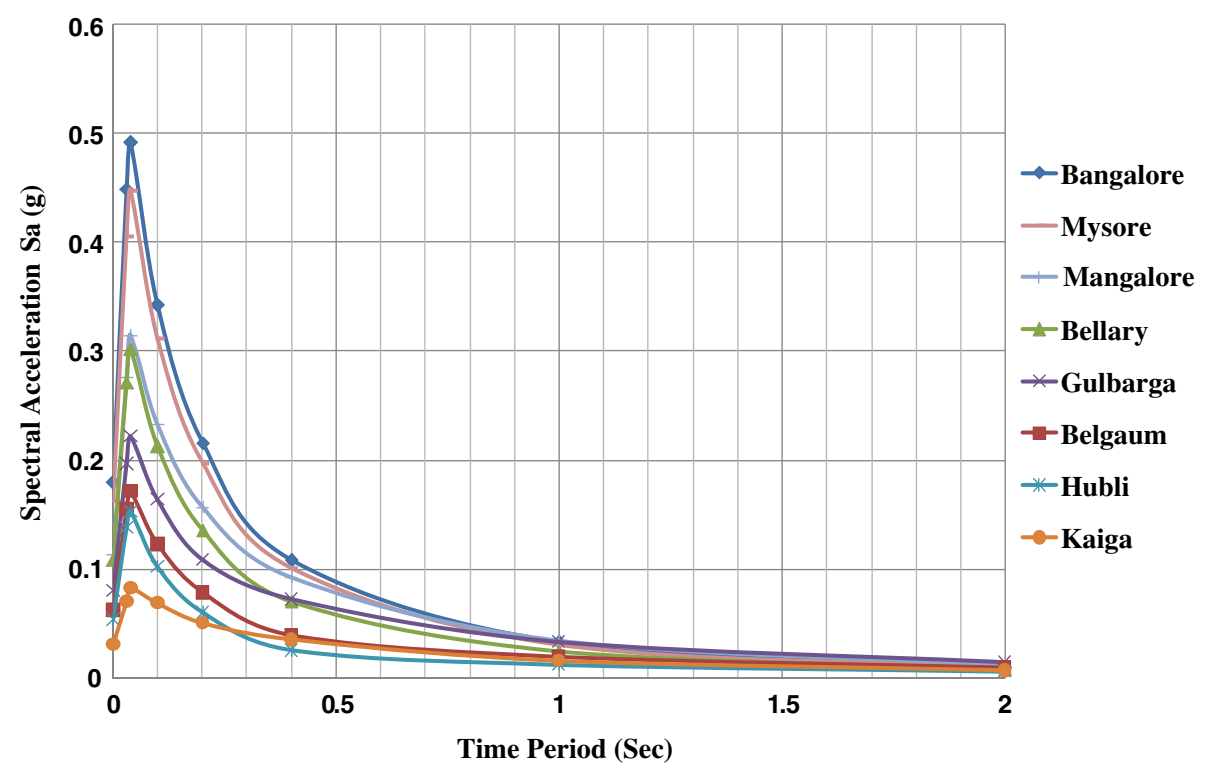

Figure 10. Response spectrum for various cities in the state of Karnataka (from DSHA).

Table 4. The exact location of major cities and corresponding PGA value from DSHA.

\begin{tabular}{lcccc}
\hline & \multicolumn{2}{c}{ Location } & & \\
\cline { 2 - 3 } Major cities & Longitude $\left({ }^{\circ} \mathrm{E}\right)$ & Latitude $\left({ }^{\circ} \mathrm{N}\right)$ & Mean PGA value $(\mathrm{g})$ & MCE $\left(M_{w}\right)$ \\
\hline Bangalore & 77.59 & 12.979 & 0.18 & 5.6 \\
Belgaum & 74.5 & 15.85 & 0.063 & 5.0 \\
Bellary & 76.92 & 15.14 & 0.11 & 5.7 \\
Gulbarga & 76.83 & 17.33 & 0.081 & 5.0 \\
Hubli & 75.13 & 15.34 & 0.054 & 5.0 \\
Kaiga & 74.43 & 14.85 & 0.031 & 6.3 \\
Mangalore & 74.84 & 12.87 & 0.114 & 5.7 \\
Mysore & 76.64 & 12.3 & 0.163 & 5.6 \\
\hline
\end{tabular}

Note: MCE - Maximum credible earthquake.

2500 years return period were developed for all major cities in Karnataka and are presented in this paper.

\section{Results}

\subsection{Using deterministic hazard analysis}

The spectral acceleration values at rock level were obtained for all the grid points using the DSHA method described above. The response spectra for some of the important cities in Karnataka were developed and the results are presented here. Spatial variation of PGA value for the entire Karnataka State is shown in figure 9. Higher PHA value, in the range of $0.35-0.45 \mathrm{~g}$ is obtained for some regions in Bidar district, in northern Karnataka, close to Maharashtra which is much higher than the value predicted by Parvez et al (2003). Analysis shows moderate to high hazard values in southern Konkan coast (near Mangalore-Udupi) region and low hazard value for interior regions of Karnataka. The analysis shows that Bangalore has highest PGA of $0.18 \mathrm{~g}$ which matches well with the value obtained by Sitharam and Anbazhagan (2006) and Vipin and Sitharam (2011). Kaiga has the lowest hazard value of 0.031 g. Similar PGA value was reported by Vipin and Sitharam (2011) for the Kaiga area using deterministic methodology. Figure 10 presents the response spectra for various cities, obtained from DSHA. The event responsible for producing maximum hazard value at a particular location is estimated separately for point source model and linear source model. The larger magnitude event obtained from either of the sources is designated as maximum credible earthquake for that location. The exact location of these cities at which these values were developed are shown in table 4 along with maximum credible earthquake (MCE). 

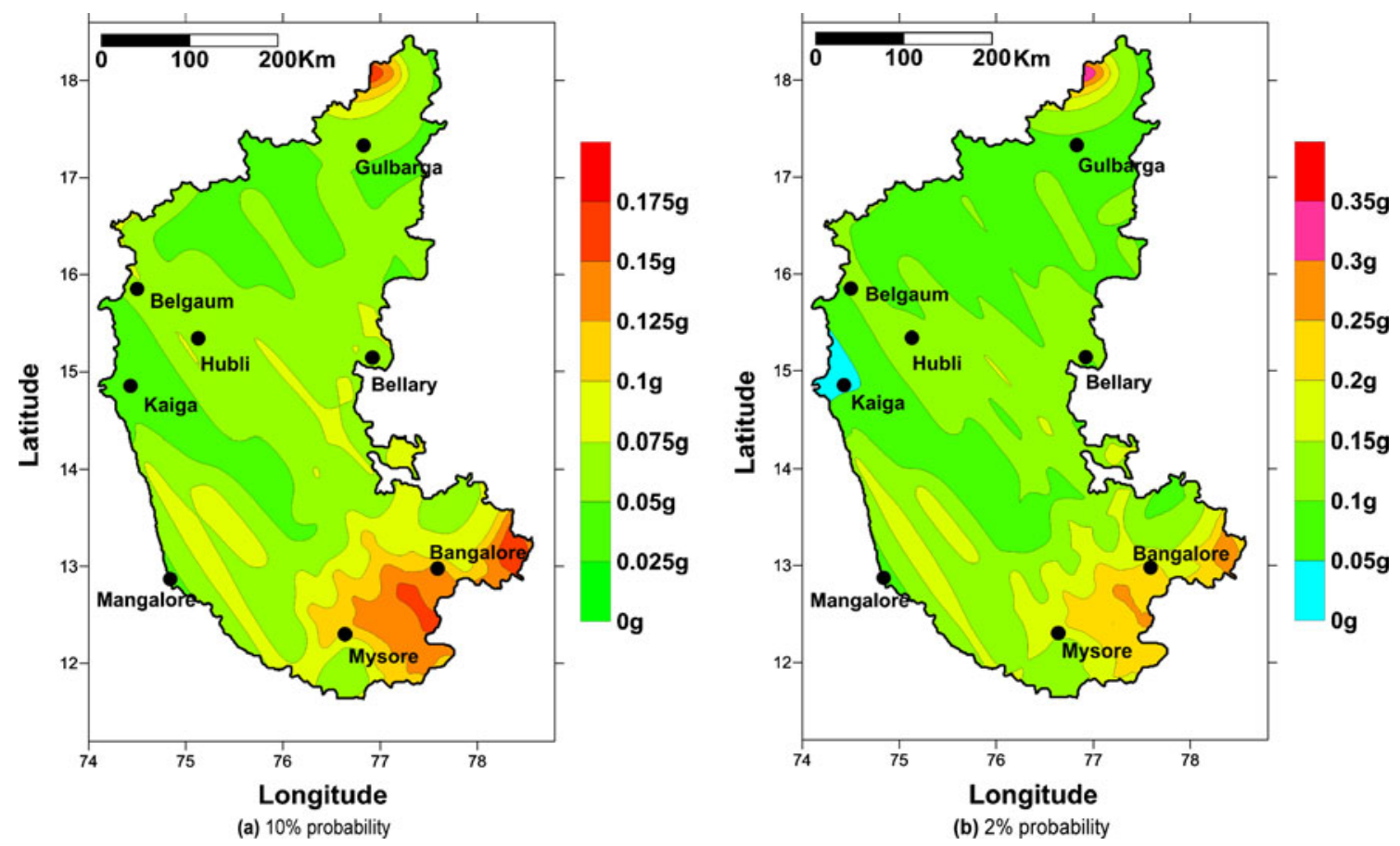

Figure 11. Spatial variation of PHA values at bedrock throughout the state of Karnataka having $10 \%$ and $2 \%$ probability of occurrence in 50 years (from PSHA).

Table 5. The exact location of major cities and corresponding PGA value from PSHA.

\begin{tabular}{lccccc}
\hline & \multicolumn{2}{c}{ Location } & & \multicolumn{2}{c}{ Mean PGA value (g) } \\
\cline { 2 - 3 } Major cities & Longitude $\left({ }^{\circ} \mathrm{E}\right)$ & Latitude $\left({ }^{\circ} \mathrm{N}\right)$ & & $10 \%$ & $2 \%$ \\
\hline Bangalore & 77.59 & 12.979 & & 0.131 & 0.228 \\
Belgaum & 74.5 & 15.85 & & 0.068 & 0.117 \\
Bellary & 76.92 & 15.14 & & 0.064 & 0.102 \\
Gulbarga & 76.83 & 17.33 & & 0.054 & 0.093 \\
Hubli & 75.13 & 15.34 & & 0.072 & 0.132 \\
Kaiga & 74.43 & 14.85 & & 0.032 & 0.045 \\
Mangalore & 74.84 & 12.87 & & 0.044 & 0.079 \\
Mysore & 76.64 & 12.3 & & 0.103 & 0.165 \\
\hline
\end{tabular}

\subsection{Using probabilistic hazard analysis}

Peak horizontal acceleration (PHA) at rock level, for the entire Karnataka State was evaluated using PSHA and the results are presented here. The spatial variation of hazard value for $10 \%$ and $2 \%$ probability of exceedance in 50 years for Karnataka State is shown in figure 11. The same is presented in a tabular form (table 5) for important cities in Karnataka. Seismic hazard corresponding to an earthquake with $10 \%$ probability of occurrence in 50 years (return period of 475 years) is commonly used for the design of normal residential and commercial buildings. While seismic hazard corresponding to an earthquake with $2 \%$ probability of occurrence in 50 years (which corresponds to a return period of 2500 years) is used for designing critical structures. The PSHA also gives high hazard values for Bidar and surrounding region. The PGA value ranges from 0.15 to $0.175 \mathrm{~g}$ for a return period of 475 years and 0.3 to $0.35 \mathrm{~g}$ for a return period of 2500 years. The hazard value obtained for Bidar and surrounding region from the present study matches with the value presented by Vipin et al (2009), but slightly higher than the value reported by Bhatia et al (1999) and Jaiswal and Sinha (2007). Figures 12 and 13 present the response spectra of selected cities in Karnataka for return periods of 475 years and 2500 years. Southern part of Konkan belt has moderate hazard values 


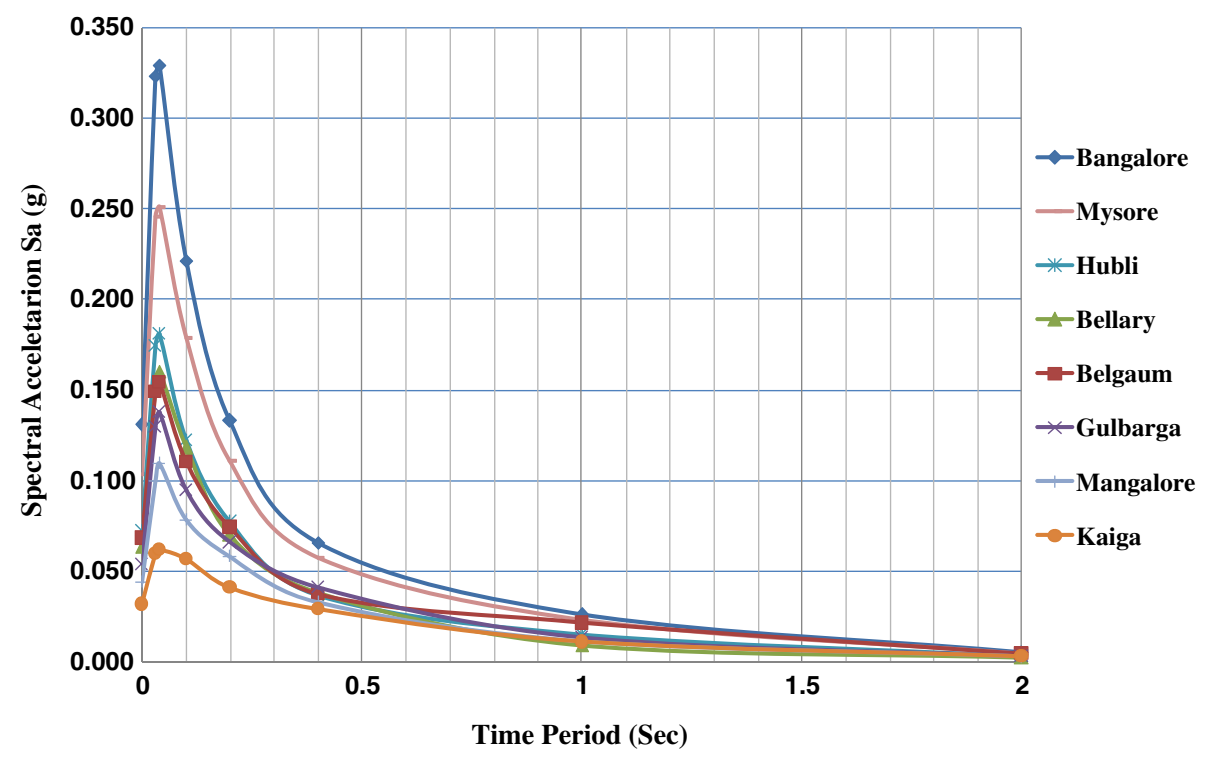

Figure 12. Response spectrum for important cities in the state of Karnataka for a return period of 475 years.

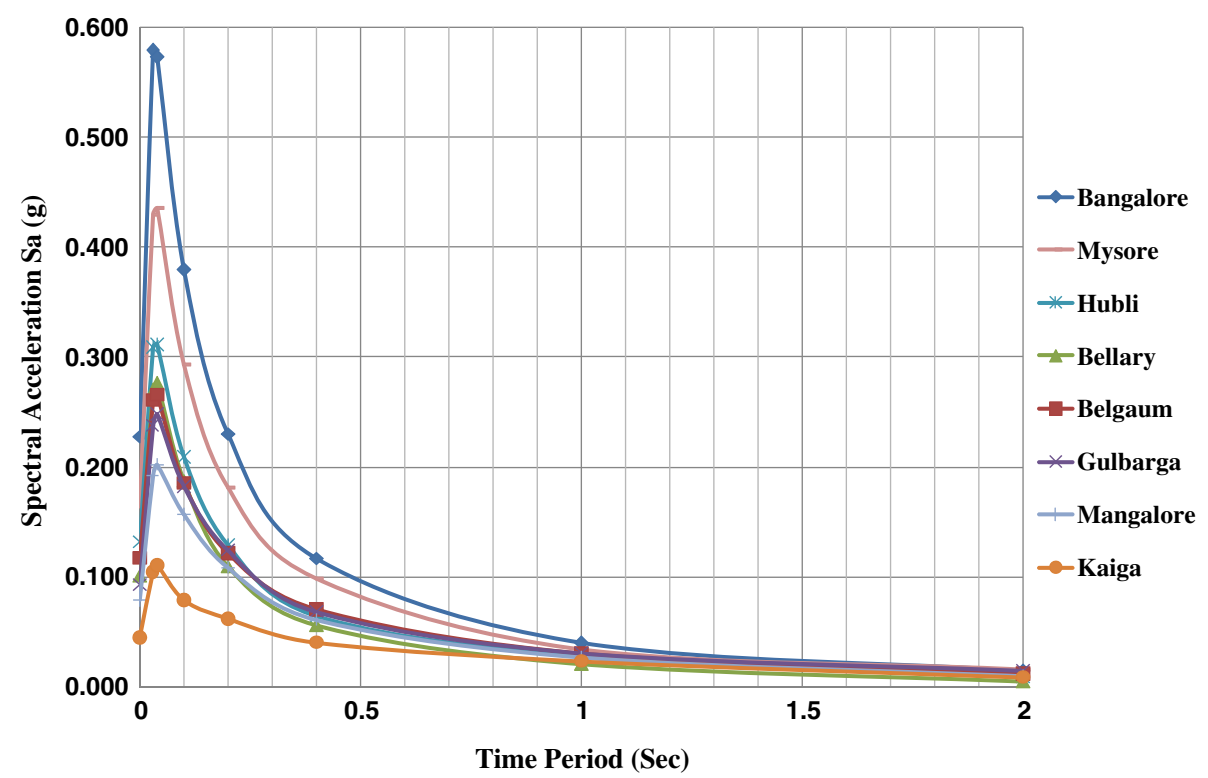

Figure 13. Response spectrum for important cities in the state of Karnataka for a return period of 2500 years.

starting from $0.1 \mathrm{~g}$ for a return period of 475 years and $0.15 \mathrm{~g}$ for a return period of 2500 years, which are similar to the values predicted by Vipin et al (2009). The hazard value for the Bangalore city corresponding to 475 years return period is $0.131 \mathrm{~g}$ which is well within the range of PGA values (0.1-0.16 g) as reported by Vipin et al (2009) for the Bangalore region. The interior regions of Karnataka surrounding Hubli, Belgaum, etc., have a lower hazard value of less than $0.1 \mathrm{~g}$. It can be noted that hazard value obtained from PSHA is less than that of DSHA, and this is due to the fact that DSHA considers the worst possible scenario. Thus the hazard values obtained from DSHA might not even occur in the life span of common structure. So to obtain hazard value which the structure can encounter in its life span, hazard curves for various cities in Karnataka were developed and are presented here (figure 14). A hazard curve is obtained by plotting mean annual rate of exceedance (MARE) against the peak horizontal acceleration (PHA). From this plot, the hazard value for any given return period can be obtained for the selected cities in Karnataka. 


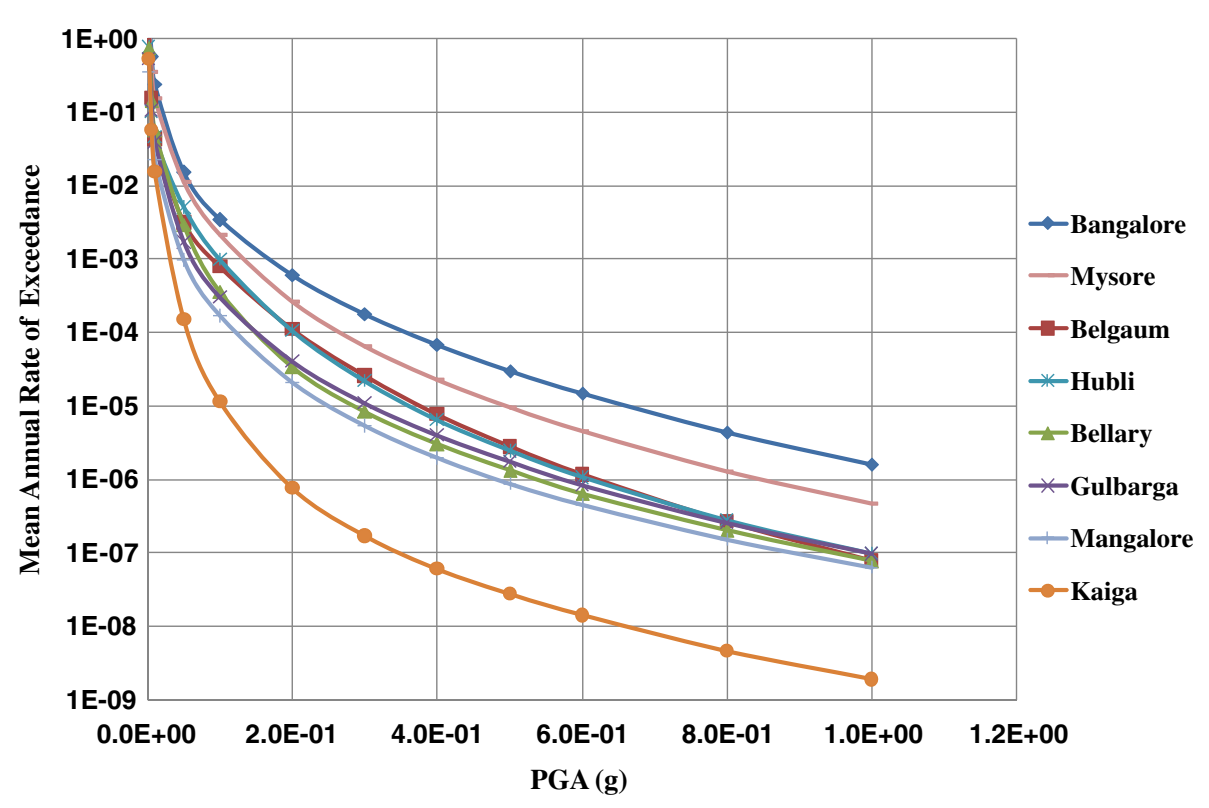

Figure 14. Hazard curve for various cities in the state of Karnataka.

\section{Conclusions}

Major conclusions from the present seismic hazard study for the state of Karnataka are given below. The PHA values were evaluated for a finer grid point and the results will be useful for the macro level planning of the state.

- Deterministic seismic hazard analysis shows the high hazard value of around $0.35 \mathrm{~g}$ for places in Bidar. Similarly from probabilistic analysis, places in Bidar district have hazard values ranging from 0.15 to $0.175 \mathrm{~g}$, for a return period of 475 years and $0.3-0.35 \mathrm{~g}$ for a return period of 2500 years. These regions are very close to the fault at Latur which has produced an earthquake of magnitude 6.1 in 1993 (Jain et al 1994).

- Region between Bangalore and Mysore are also found to have significantly high value of PHA of about $0.10-0.25 \mathrm{~g}$ from DSHA and PSHA analysis. But as per BIS-1893 (2002), this region is delineated as zone 2 which is the least active zone. From the seismotectonic atlas of the study area (figure 6), it can be found that large number of events have occurred in this region and the obtained PHA value from both DSHA and PSHA studies points that this region is not the safest zone as described by Indian seismic code.

- DSHA results give PHA value of more than $0.25 \mathrm{~g}$ for Mangalore-Udupi regions. BIS-1893 (2002) categorizes this region as zone 3 which is justifiable when comparing BIS-1893 (2002) maps (figure 1) and the hazard maps obtained from DSHA and PSHA (figures 9 and 11).
- Seismic hazard analysis also indicates that the interior regions in Karnataka are having low hazard values. Kaiga, which is the location for nuclear power plant, is having relatively low seismic hazard. But Indian seismic code has overestimated the hazard value in this area by delineating it to zone 3.

- The response spectra, which are presented for the important cities in Karnataka, can be used in design purposes. BIS-1893 (2002) provides a unique response spectrum (at rock level) for seismic design throughout India, is somewhat primitive. Figures 10, 12 and 13 show that the response spectrum for each city is different from the other and hence using a unique response spectrum for design purpose throughout India is an outdated practice.

- The PHA values obtained in the present study (based on DSHA and PSHA) match well with the values obtained by other researchers for different parts of the study area.

\section{Acknowledgements}

The authors thank CiSTUP and STC (ISRO-IISc joint initiative), Indian Institute of Science, Bangalore, India for funding the project titled 'Probabilistic Seismic Hazard assessment of Karnataka State' (Ref. No. CIST 017 dated 1 January 2010). Most of the earthquake data for this work were collected from the following websites http:// www.earthquakeinfo.org/Catalog_Data.htm, http:// www.iris.edu/, http://www.imd.ernet.in, http:// www.ncedc.org, http://asc-india.org/, http://www. 
isc.ac.uk/search/bulletin/rectang.html, http:// earthquake.sgs.gov/regional/neic/ and database from Gauribidanur Array provided by NGRI, Hyderabad and IGCAR, Kalpakkam.

\section{References}

Anbazhagan P, Vinod J S and Sitharam T G 2009 Probabilistic seismic hazard analysis for Bangalore; Natural Hazards 48 145-166.

Atkinson G M and Boore D M 2006 Earthquake groundmotion prediction equations for eastern north America; Bull. Seismol. Soc. Am. 96(6) 2181-2205.

Basu S and Nigam N C 1977 Seismic risk analysis of Indian peninsula; Proc. 6th World Conf. Earthqu. Engg., New Delhi 1 782-788.

Bhatia S C, Ravi Kumar M and Gupta H K 1999 A probabilistic seismic hazard map of India and adjoining regions; Annali De Geofisica 46(2) 1154-1164.

BIS-1893 2002 Indian Standard criteria for earthquake resistant design of structures. Part 1: General provisions and buildings; Bureau of Indian Standards, New Delhi.

Bommer J J, Scherbaum F, Bungum H, Cotton F, Sabetta $\mathrm{F}$ and Abrahamson N A 2005 On the use of logic trees for ground-motion prediction equations in seismic hazard analysis; Bull. Seismol. Soc. Am. 95 377-389.

Chandra U 1977 Earthquakes of peninsular India - A seismotectonic study; Bull. Seismol. Soc. Am. 67(5) 1387-1413.

Cornell C A 1968 Engineering seismic risk analysis; Bull. Seismol. Soc. Am. 58 1583-1606.

Costa G, Panza G F, Suhadolc P and Vaccari F 1993 Zoning of the Italian territory in terms of expected peak ground acceleration derived from complete synthetic seismograms; In: Geophysical Exploration in Areas of Complex Geology, II (eds) Cassinis R, Helbig K and Panza G F, J. Appl. Geophys. 30 149-160.

Frankel A 1995 Mapping seismic hazard in the Central Eastern United States; Seismol. Res. Lett. 66(4) 8-21.

Gangrade B K and Arora S K 2000 Seismicity of the Indian peninsular shield from regional earthquake data; Pure Appl. Geophys. 157 1683-1705.

Gubin I E 1968 Seismic zoning of Indian peninsula; Bull. Int. Inst. Seismol. Earthquake Eng. 5 109-139.

Guha S K 1962 Seismic regionalization of India; 2nd Symposium Earthquake Engineering, Roorkee, pp. 191-207.

Gutenberg B and Richter C F 1944 Frequency of earthquakes in California; Bull. Seismol. Soc. Am. 34 185-188.

Heaton T H, Tajima T F and Mori A W 1986 Estimating ground motions using recorded accelerograms; Surv. Geophys. 8 25-83.

Iyengar R N, Sharama D and Siddiqui J M 1999 Earthquake history of India in Medieval times; Indian J. History Sci. 34(3) 181-237.

Jain S K, Murty C V R, Chandak N, Seeber L and Jain N K 1994 The September 29, 1993, M6.4 Killari, Maharashtra Earthquake in Central India; EERI Special Earthquake Report, EERI Newsletter 28(1).

Jaiswal K and Sinha R 2007 Probabilistic seismic-hazard estimation for peninsular India; Bull. Seismol. Soc. Am. 97(1B) 318-330.

Kaila K L and Rao N M 1979 Seismic zoning maps of the Indian subcontinent; Geophys. Res. Bull. 17 293-301.

Kaila K L, Gaur V K and Hari N 1972 Quantitative seismicity maps of India; Bull. Seismol. Soc. Am. 62 1119-1131.
Khatri K N, Rogers A M and Algermissen S T 1984 A seismic hazard map of India and adjacent areas; Tectonophys. 108 93-134.

Kramer S L 1996 Geotechnical Earthquake Engineering; Pearson Education Pvt. Ltd, Delhi, India, Reprinted in 2003.

Krishna J 1959 Seismic zoning of India; Earthquake Engineering, Seminar, Roorkee University, India, pp. $32-38$.

Kumar P, Yuan X, Kumar M R, Kind R, Li X and Chadha R K 2007 The rapid drift of the Indian tectonic plate; Nature 449 894-897.

Menon A, Ornthammarath T, Corigliano M and Lai C G 2010 Probabilistic seismic hazard macrozonation of Tamil Nadu in southern India; Bull. Seismol. Soc. Am. 100(3) 1320-1341.

Parvez I A, Vaccari F and Panza G F 2003 A deterministic seismic hazard map of India and adjacent area; Geophys. J. Int. 155 489-508.

Panza G F, Vaccari F and Cazzaro R 1999 Deterministic seismic hazard assessment; In: Vrancea, Earthquakes: Tectonic and risk mitigation (eds) Wenzel F et al (The Netherlands: Kluwer Academic Publishers), pp. 269286.

Raghu Kanth S T G and Iyengar R N 2007 Estimation of seismic spectral acceleration in Peninsular India; J. Earth Syst. Sci. 116(3) 199-214.

Ram A and Rathor H S 1970 On frequency magnitude and energy of significant Indian earthquakes; Pure Appl. Geophys. 79 26-32.

Ramalingeswara Rao B and Sitapathi Rao P 1984 Historical seismicity of peninsular India; Bull. Seismol. Soc. Am. 74 2519-2533.

Ramasamy S M 2006 Remote sensing and active tectonics of South India; Int. J. Remote Sens. 27(20) 43974431.

Reiter L 1990 Earthquake hazard analysis: Issues and insights; Columbia University Press, New York, USA.

Scordilis E M 2006 Empirical global relations converting $\mathrm{M}_{s}$ and $\mathrm{m}_{b}$ to moment magnitude; J. Seismol. 10 $225-236$.

SEISAT 2000 Seismotectonic Atlas of India; Geological Survey of India, New Delhi.

Stepp J C 1972 Analysis of the completeness of the earthquake sample in the Puget Sound area and its effects on statistical estimates of earthquakes hazard; In: Proc. Int. Conf. Microzonation for Safer Construct, Res. Appl., Seattle, Washington 64(4) 1189-1207.

Sitharam T G and Anbazhagan P 2006 Seismic hazard analysis for the Bangalore region, Natural Hazards 40 261-278.

Sitharam T G, Anbazhagan P and Ganesha Raj K 2006 Use of remote sensing and seismotectonic parameters for seismic hazard analysis of Bangalore; Nat. Hazards Earth Syst. Sci. 6 927-939.

Sitharam T G and Vipin K S 2011 Evaluation of spatial variation of peak ground acceleration and spectral acceleration for south India: Probabilistic approach; Natural Hazards 59(2) 639-653, doi: 10.1007/s11069-0119784-x.

Tandon A N 1956 Zoning of India liable to earthquake damage; Indian J. Meteorol. Geophys. 10 137-146.

Toro G N, Abrahamson N and Schneider J 1997 Model of strong ground motions from earthquakes in central and eastern North America: Best estimates and uncertainties; Seismol. Res. Lett. 68 41-57.

Vipin K S, Anbazhagan P and Sitharam T G 2009 Estimation of peak ground acceleration and spectral acceleration for South India with local site effects: 
Probabilistic approach; Nat. Hazards Earth Syst. Sci. 9 865-878.

Vipin K S and Sitharam T G 2011 Multiple source and attenuation relationships for evaluation of deterministic seismic hazard: Logic tree approach considering the geology and local site effects; Georisk 5(3-4) 173-185, doi: 10.1080/17499518.2010.532015.
Walling M Y and Mohanty W K 2009 An overview on the seismic zonation and microzonation studies in India; Earth Sci. Rev. 96 67-91.

Wang Z 2005 Discussion - Klügel, J-U 2005 problems in the application of the SSHAC probability method for assessing earthquake hazards at Swiss nuclear power plants; Eng. Geology 78 285-307.

MS received 20 November 2010; revised 22 October 2011; accepted 1 November 2011 